Article

\title{
Characterization of the Key Aroma Compounds in Chinese Syrah Wine by Gas Chromatography-Olfactometry-Mass Spectrometry and Aroma Reconstitution Studies
}

\author{
Pengtao Zhao ${ }^{1, \dagger}$, Jinxin Gao ${ }^{1,+}$, Michael Qian ${ }^{2}$ and Hua $\mathrm{Li}^{1,3, *}$ \\ 1 College of Enology, Northwest A\&F University, Yangling 712100, Shaanxi, China; \\ zpt5232@Gmail.com (P.Z.); jasminexy2016@icloud.com (J.G.) \\ 2 Department of Food Science \& Technology, Oregon State University, Corvallis, OR 97333, USA; \\ Michael.qian@oregonstate.edu \\ 3 Shaanxi Engineering Research Center for Viti-Viniculture, Yangling 712100, Shaanxi, China \\ * Correspondence: lihuawine@nwsuaf.edu.cn; Tel./Fax: +86-29-8708-2805 \\ + These authors contribute equally to this paper.
}

Received: 5 May 2017; Accepted: 20 June 2017; Published: 24 June 2017

\begin{abstract}
The key aroma compounds and the organoleptic quality of two Chinese Syrah wines from the Yunnan Shangri-La region and Ningxia Helan mountain region were characterized. The most important eighty aroma-active compounds were identified by Gas Chromatography-Olfactometry. In both Syrah samples, ethyl 2-methylpropanoate, ethyl 3-methylbutanoate, 3-methylbutyl acetate, 2- and 3-methyl-1-butanol, ethyl hexanoate, ethyl octanoate, 2-phenethyl acetate, methional, 3-methylbutanoic acid, hexanoic acid, octanoic acid, $\beta$-damascenone, guaiacol, 2-phenylethanol, trans-whiskylactone, 4-ethylguaiacol, eugenol, 4-ethylphenol, and sotolon were detected to have the highest odor intensities. In the chemical analysis, 72 compounds were quantitated by Stir Bar Sorptive Extraction combined with Gas Chromatography Mass Spectrometry. Based on the Odor Activity Value (OAV), the aromas were reconstituted by combining aroma compounds in the synthetic wine, and sensory descriptive analysis was used to verify the chemical data. Fatty acid ethyl esters, acetate esters, and $\beta$-damascenone were found with higher OAVs in the more fruity-smelling sample of Helan Mountain rather than Shangri-La.
\end{abstract}

Keywords: Syrah wine; aroma compounds; GC-O; SBSE; OAV; sensory descriptive analysis

\section{Introduction}

Wine aroma characteristics originate from grape berries, wine fermentation, and aging techniques [1,2]. Over one thousand volatile and semi-volatile compounds have been identified in wine contributing to its aroma quality [3]. High contributing aroma-active volatiles in wine include alcohols, esters, fatty acids, ketones, terpenes, phenols, and aldehydes. They exist in varying concentrations, from $10^{-12}$ to $10^{-4} \mathrm{~g} / \mathrm{L}[4,5]$. Volatiles in wine are complex and heterogeneous, and those concentrations that are higher than their odor threshold are considered as potential contributors to wine aroma [6-9].

Solid Phase Extraction (SPE) based on LiChrolut-EN is a fast and user friendly technique that has been widely utilized to isolate and concentrate volatile compounds in wine [10]. This technique concentrates and purifies the analytes by adsorbing the compounds onto the resin bed and recovering them using a small volume of suitable solvents [11]. Solid Phase Microextraction (SPME) and Stir Bar Sorptive Extraction (SBSE) techniques based on polydimethylsiloxane (PDMS) as the absorbent for nonpolar and intermediate polar compounds are of high selectivity and only require a small amount 
of sample. They are rapid and easy to perform techniques, and their use has been increasing for the analysis of different types of volatile compounds in wine [9-12]. Compared to SPME, SBSE is far more sensitive since its stir bar has much more sorbent volume to extract and concentrate analytes from a larger sample volume [13]. SBSE could be performed for the extraction of those compounds with low concentration or low affinity. PDMS coated stir bars and ethylene glycol-silicone (EG) coated stir bars are the two most frequently used extraction materials in wine flavor chemistry research [12-14]. Nie and Albinus [15] reported that both EG-Silicone-SBSE and derivatization-PDMS-SBSE types were successfully applied for the quantitative analysis of volatile phenols in beverages. Good linearity and repeatability were obtained.

With the application of gas chromatography-olfactometry (GC-O), the most potent odorants in wine have been identified. Meanwhile, by quantitative analysis of the aroma-active compounds, odor activity values (OAVs) of the potential contributors were obtained, which reflect their significance to the aroma profile of wine. The connection of flavor chemistry with GC-O techniques has allowed for associating wine sensory properties to specific chemical compounds [16-20].

Syrah (Vitis vinifera L. cv.) originally from Rhone valley (France) has been very popular for its full-bodied, dark fruit flavors, berry-like aroma, and is often described as having spicy or pepper-like attributes [21]. Despite the importance of Syrah to the wine industry, little is known about the aroma compounds that are responsible for the perceived aroma of Syrah wine. Wine grapes grown in different climatic and geographical areas led to a diverse expression of varietal characteristics [22]. Mayr et al. [23] characterized two premium Syrah wine from Australia using GC-O, quantitation, and aroma reconstitution techniques. Approximately 60 odorants were detected from the liquid extract and the dynamic headspace of Syrah wine; ethyl butanoate, ethyl 2-methylbutanoate, ethyl 3-methylbutanoate, 2- and 3-methyl-1-butanol, ethyl hexanoate, furfuryl ethyl ether, $\beta$-damascenone, guaiacol, and 2-phenylethanol were detected to have the highest Aroma Extract Dilution Analysis (AEDA) values. They selected the 48 most important compounds that were quantitatively analyzed. According to OAV, ethyl octanoate, ethyl hexanoate, ethyl 3-methylbutanoate, ethyl 2-methylbutanoate, ethyl acetate, $\beta$-damascenone, 3-methyl butanoic acid, eugenol, and cis-whisky lactone were found to be the most significant contributors to Syrah wine aroma.

With the rapid development of the wine industry in China, the quality of Chinese wine is improving quickly and appeals to more and more consumers. The Shangri-La plateau region located in the core area of Yunnan province, southwestern China, is one of the world's highest altitude vineyards with an average elevation of over $2400 \mathrm{~m}$. The highest quality vineyard on both sides of the Jinsha River, Lancang River valley slope is one of the most characteristic vineyards in China [24]. The Ningxia eastern Helan Mountain region located in the northwestern region of China is a wide, heavily irrigated valley between the Yellow River and the base of Helan Mountain. Ningxia has a thoroughly continental climate and high altitude of the vineyards (more than $1000 \mathrm{~m}$ above sea level). It has proved to be one of China's most promising vineyard areas [25].

In the past few decades, wine from China, especially Helan Mountain and Shangri-La, are attracting attention from all over the world and earning more and more recognition. Winemakers are therefore further investing in their potential. However, no comprehensive aroma characterization of Syrah wine in China has been conducted. The present paper aimed to determine the key aroma and aroma potentials of two Syrah wines from China. The main correlations between the chemical composition and the sensory properties were established.

\section{Results}

\subsection{Identification of Aroma Compounds by GC-O}

Potential volatile fractions in the concentrated extracts were determined by GC-O. The results listed in Table 1 show 79 compounds that were detected in the two Syrah wines, including esters, higher alcohols, volatile phenols, fatty acids, ketones and lactones, aromatic compounds, and sulfides, 
which were determined to play significant roles in wine aroma quality. In the GC-O study, the odorants in the extracts were described as fruity, floral, green, spicy, tobacco, woody, potato, nutty, herb, brandy, sweaty, and so on.

The highest intensities of the compounds identified in Ningxia Syrah sample (NS) and Yunnan Syrah sample (YS) were found for ethyl 2-methylpropanoate, ethyl 3-methylbutanoate, 3-methylbutyl acetate, 2- and 3-methyl-1-butanol, ethyl hexanoate, ethyl octanoate, 2-phenethyl acetate, methional, 3-methylbutanoic acid, hexanoic acid, octanoic acid, $\beta$-damascenone, guaiacol, 2-phenylethanol, trans-whisky lactone, 4-ethylguaiacol, eugenol, 4-ethylphenol, and sotolon. They were detected to have odor intensities $\geq 3.0$ in at least one Syrah extract. The two Syrah wine samples showed very similar odorant contents and the proportion of volatile components. Esters (21 compounds), volatile phenols (13), fusel alcohols (11), fatty acids (8), and $C_{13}$-norisoprenoids (2) groups were considered as the main contributors to wine aroma. The aroma contributors of Chinese Syrah reported in this study were consistent with the research by Mayr et al. [23] on two Syrah wine from the warmer Barossa Valley and the cooler Margaret River Syrah.

Some studies reported links of odorants with sensory attributes in wine which showed positive correlations between fruity (berry or dried fruit) and ethyl ester compounds [21,26], woody aromas, and volatile phenols [27]. Straight and branched chain fatty acids such as propionic acid, 3-methylbutyric acid, hexanoic acid, and octanoic acid in wine $\left(10^{-6} \mathrm{~g} / \mathrm{L}\right.$ level concentration) were considered as unpleasant odorants, but they contribute significantly to the complexity of the wine total flavor [28]. $\mathrm{C}_{13}$-norisoprenoid compounds $\beta$-damascenone (fruity-flowery smelling) and $\beta$-ionone (violet smelling) were reported frequently in premium wine $[29,30]$. To understand the correlations between volatile compounds and aroma attributes, two samples are comparatively discussed in the GC-O section, quantitative analysis section, and aroma reconstitution test section. Compared with YS, NS showed higher intensities in odorants: 3-methylbutyl acetate, ethyl hexanoate, ethyl octanoate, methional, benzaldehyde, ethyl decanoate, guaiacol, trans-whiskylactone, $\gamma$-decalactone, sotolon, and ethyl vanillate. These compounds mainly contribute to the fruity, nutty, and clove characters of wine. In contrast, compounds 1,1-diethoxyethane, 2-methylpropanoic acid, $\alpha$-terpineol, octanoic acid, and $m$-cresol in NS were detected to have lower odor intensities than that in YS.

Table 1. Odorants identified by Solid Phase Extraction-Gas Chromatography-Olfactometry (SPE-GC-O) in the two Syrah wines.

\begin{tabular}{|c|c|c|c|c|c|}
\hline No. & Aroma Compounds ${ }^{a}$ & $\mathbf{R I}_{\text {ZB-wax }} \mathbf{b}$ & Odor Descriptions & \multicolumn{2}{|c|}{ Odor Intensity of ${ }^{\mathrm{c}}$} \\
\hline 1 & 1,1-diethoxyethane & 872 & fruity, berry & 1.5 & 2.0 \\
\hline 3 & ethyl propanoate & 965 & fruity & 2.7 & 2.5 \\
\hline 4 & ethyl 2-methylpropanoate & 974 & fruity & 3.7 & 3.5 \\
\hline 7 & ethyl butanoate & 1041 & dry fruit & 2.8 & 2.7 \\
\hline 8 & butyl acetate & 1056 & fruity & 2.8 & 2.7 \\
\hline 9 & ethyl 2-methylbutyrate & 1060 & fruity & 2.7 & 2.3 \\
\hline 10 & 2,3-pentanedione & 1069 & sour, fruity & 2.0 & 2.3 \\
\hline 11 & ethyl 3-methylbutanoate & 1074 & fruity & 3.5 & 3.5 \\
\hline 16 & 2- and 3-methyl-1-butanol & 1223 & medicine, brandy & 5.0 & 5.0 \\
\hline 17 & ethyl hexanoate & 1247 & fruity & 3.3 & 2.7 \\
\hline 18 & hexyl acetate & 1268 & fruity & 1.5 & 1.3 \\
\hline 19 & 3-hydroxy-2-butanone & 1297 & fruity & 2.5 & 2.3 \\
\hline 20 & 1-octen-3-one & 1310 & mushroom & 1.2 & 1.5 \\
\hline
\end{tabular}


Table 1. Cont.

\begin{tabular}{|c|c|c|c|c|c|}
\hline \multirow{2}{*}{ No. } & \multirow{2}{*}{ Aroma Compounds a } & \multirow{2}{*}{$\mathbf{R I}_{\text {ZB-wax }}{ }^{\mathrm{b}}$} & \multirow{2}{*}{ Odor Descriptions } & \multicolumn{2}{|c|}{ Odor Intensity of } \\
\hline & & & & NS & YS \\
\hline 21 & 3-methylpentanol & 1335 & fruity, green & 1.5 & 1.3 \\
\hline 22 & ethyl lactate & 1351 & fruity & 1.0 & 1.3 \\
\hline 23 & 1-hexanol & 1364 & green & 2.7 & 2.5 \\
\hline 24 & cis-3-hexenol & 1401 & green & 1.7 & 1.5 \\
\hline 25 & trans-2-hexenol & 1424 & green & 1.5 & 1.3 \\
\hline 26 & 3-isopropyl-2-methoxypyrazine & 1441 & green pepper & 1.7 & 1.5 \\
\hline 27 & ethyl octanoate & 1444 & fruity, floral & 3.5 & 2.3 \\
\hline 28 & 1-octen-3-ol & 1461 & mushroom & 1.0 & 1.3 \\
\hline 29 & methional & 1465 & potato & 3.5 & 3.0 \\
\hline 30 & furfural & 1483 & woody & 1.5 & 1.7 \\
\hline 31 & 3-sec-butyl-2-methoxypyrazine & 1510 & bell pepper & 2.0 & 2.0 \\
\hline 32 & benzaldehyde & 1525 & almond & 2.8 & 2.0 \\
\hline 33 & 3-isobutyl-2-methoxypyrazine & 1542 & pepper & 1.5 & 1.3 \\
\hline 34 & 2-(methylthio) ethanol & 1552 & potato & 2.2 & 2.3 \\
\hline 35 & linalool & 1571 & floral, citrus & 1.2 & 1.5 \\
\hline 36 & ethyl 3-methylthiopropionate & 1583 & metallic, onion & 1.7 & 1.3 \\
\hline 37 & 2-methylpropanoic acid & 1588 & cheesy & 1.5 & 2.0 \\
\hline 38 & butanoic acid & 1628 & sweaty & 2.2 & 2.0 \\
\hline 39 & $\gamma$-butyrolactone & 1642 & nutty & 1.2 & 1.0 \\
\hline 40 & ethyl decanoate & 1651 & fruity & 2.2 & 1.7 \\
\hline 41 & furfuryl alcohol & 1679 & sweet, nutty & 1.7 & 1.7 \\
\hline 42 & 3-methylbutanoic acid & 1687 & sweaty & 5.0 & 5.0 \\
\hline 43 & $\alpha$-terpineol & 1708 & floral & 2.7 & 3.2 \\
\hline 44 & 3-(methylthio)propanol & 1738 & potato & 2.2 & 2.0 \\
\hline 45 & $\beta$-citronellol & 1759 & floral & 2.0 & 2.0 \\
\hline 46 & 2-phenethyl acetate & 1828 & bread, sweet & 2.7 & 3.0 \\
\hline 47 & $\beta$-damascenone & 1841 & tobacco, burnt sugar & 4.2 & 4.0 \\
\hline 48 & hexanoic acid & 1860 & sweaty & 2.8 & 3.0 \\
\hline 49 & geraniol & 1865 & citrus, floral & 1.7 & 2.0 \\
\hline 50 & guaiacol & 1872 & phenolic, spicy & 3.3 & 2.7 \\
\hline 51 & benzyl alcohol & 1890 & floral & 2.8 & 2.7 \\
\hline 52 & cis-whisky lactone & 1908 & nutty, wood & 3.5 & 3.8 \\
\hline 53 & 2-phenylethanol & 1935 & floral, rose & 4.5 & 4.2 \\
\hline 54 & $\beta$-ionone & 1965 & floral & 1.7 & 1.5 \\
\hline 55 & trans-whisky lactone & 1975 & nutty, coconut & 2.5 & 2.0 \\
\hline 56 & trans-2-hexenoic acid & 1989 & cheesy, herbal & 1.7 & 1.7 \\
\hline 57 & $o$-cresol & 2007 & woody, phenolic & 2.8 & 1.7 \\
\hline 58 & 4-ethylguaiacol & 2040 & caramellic & 3.3 & 3.2 \\
\hline 59 & $\gamma$-nonalactone & 2049 & nutty, woody & 1.5 & 1.3 \\
\hline 60 & furaneol & 2065 & burnt sugar & 3.5 & 3.2 \\
\hline 61 & octanoic acid & 2078 & sweaty & 2.8 & 3.2 \\
\hline 62 & p-cresol & 2087 & horse & 1.7 & 1.3 \\
\hline 63 & $m$-cresol & 2103 & leather & 1.5 & 2.0 \\
\hline 64 & $\gamma$-decalactone & 2149 & fiber wood, sweet & 2.5 & 1.5 \\
\hline 65 & ethyl cinnamate & 2160 & spice, sweet & 2.5 & 2.0 \\
\hline 66 & eugenol & 2179 & honey, clove & 3.5 & 2.7 \\
\hline 67 & 4-ethylphenol & 2194 & medicine, horse & 2.5 & 2.7 \\
\hline 68 & 4-vinylguaiacol & 2218 & spice, anise & 2.7 & 2.5 \\
\hline 69 & sotolon & 2247 & honey, caramel & 3.3 & 2.7 \\
\hline 70 & 2,6-dimethoxyphenol & 2282 & woody, phenolic & 1.7 & 1.7 \\
\hline 71 & decanoic acid & 2286 & woody, rancid & 2.7 & 1.3 \\
\hline 72 & ethyl anthranilate & 2291 & spice, sweet & 2.7 & 1.7 \\
\hline 73 & isoeugenol & 2366 & sweet, floral & 2.0 & 2.0 \\
\hline 74 & 4-vinylphenol & 2410 & chemical, smoky & 2.7 & 1.7 \\
\hline 75 & phenylacetic acid & 2575 & honey, rose & 2.5 & 2.0 \\
\hline 76 & vanillin & 2584 & vanilla & 2.7 & 1.7 \\
\hline 77 & methyl vanillate & 2616 & vanilla & 1.8 & 2.0 \\
\hline 78 & ethyl vanillate & 2658 & vanilla & 1.5 & 1.0 \\
\hline 79 & acetovanillone & 2670 & fruity, vanilla & 1.7 & 1.3 \\
\hline
\end{tabular}

a Identification based on RI (compare retention index with authentic standards) and MS (mass spectrometry) or aroma description (A); ${ }^{b}$ RI = retention index; ${ }^{c}$ NS means Syrah wine from Ningxia Helan Mountain, YS from Yunnan Shangri-La. 


\subsection{Quantitative Analysis of Aroma-Active Compounds}

To gain insight into the aroma characteristics of the two Syrah wines, 72 important compounds (shown in Table 2), from the GC-O data and from the literature [23,31] were quantitated and their odor activity values (OAVs) were calculated. As expected, volatiles were detected at levels ranging from $\mathrm{ng} / \mathrm{L}$ to $\mathrm{mg} / \mathrm{L}$. The highest concentration in both wines was found for isoamyl alcohol $(123 \mathrm{mg} / \mathrm{L}$ for NS and $106 \mathrm{mg} / \mathrm{L}$ for YS), followed by ethyl acetate, isobutyl alcohol, propanol, diethyl succinate, 2-phenethanol, and acetaldehyde. Since those fermentation byproducts have a relatively high odor threshold (especially diethyl succinate of $120 \mathrm{mg} / \mathrm{L}$ and 2-phenethanol of $14 \mathrm{mg} / \mathrm{L}$ ), they were usually not necessarily considered as high aroma contributors to wine. Among the 72 quantitated compounds, in the Ningxia Syrah wine, 18 compounds reached concentrations higher than their odor threshold, whereas in the Shangri-La Syrah, 19 compounds were found to have an OAV $>1$. Those aroma-active compounds (23 compounds in NS and 24 compounds in YS) with OAV between 0.1 and 1 may also contribute to the formation of wine aroma due to the interaction effect in the wine matrix. In the wine from the Ningxia Helan Mountain region, these fusel alcohols were at higher concentrations than that in YS.

According to the odor threshold, the highest OAV in the Syrah from the Ningxia region was determined for $\beta$-damascenone (tobacco and burnt sugar smelling, OAV 56.1), followed by the fruity-like ethyl octanoate (OAV 54.9), and acetaldehyde (fruity and musty or pungent smelling, OAV 44.7). The fruity straight and branched esters ethyl isovalerate (OAV 43.8), ethyl hexanoate (OAV 38.1), ethyl isobutyrate (OAV 17.6), and isoamyl acetate (OAV 13.6) also had high OAVs are therefore very significant aroma contributors in NS. Those ester compounds produced by yeasts during fermentation are well known to contribute to and enhance the fruity aroma of wines [32]. $\beta$-Damascenone and $\beta$-ionone mainly come from the degradation of carotenoids in grapes, and are well known as important characteristic flavor compounds in wine, which were characterized by "fruity-flowery" and "violet" notes $[33,34]$. They are important $C_{13}$-norisoprenoids due to their low odor threshold and high contribution to wine aroma complexity $[29,30]$. Fatty acids are the precursors of esters, terpenes, and alcohols in grapes and wine that mainly contribute to the flavor of wine [32]. Butanoic acid, 2and 3-methylbutyric acid, hexanoic acid, and octanoic acid that give a cheesy or sweaty smell and contribute complexity to wine also had concentrations higher than their thresholds. Volatile acids in wine are important components in flavor quality; they impart woody, brandy, almond, etc., pleasant aromas to wine in proper concentration levels, while high concentrations (above $20 \mathrm{mg} / \mathrm{L}$ ) of acids will give a negative aroma hints of wine [20,21]. Oak-derived phenolic compounds guaiacol (OAV 1.25), eugenol (OAV 1.12) and ethyl dihydrocinnamate (OAV 1.05) were also found in concentrations above their thresholds, and they were reported as important aroma potentials in aged wine. Most of these compounds are formed through hydrolysis of glycosidically conjugated forms during wine aging, or are extracted from oak during barrel aging, contributing floral and cherry notes to wine [3-5,35].

In the Syrah wine from the Shangri-La region, compounds with the highest OAVs were mostly similar to those in NS. Unlike Syrah from the Ningxia region, acetaldehyde (OAV 63.8) was the highest in YS. The fruity-smelling ester compounds ethyl isovalerate (OAV 27.3), ethyl octanoate (OAV 11.7), ethyl hexanoate (OAV 10.8), ethyl isobutyrate (OAV 10.9), and isoamyl acetate (OAV 8.1) in YS were detected to have much lower OAVs compared with those in NS. The high concentration of acetaldehyde and lower concentration of esters in YS were supposed to be generated during relatively high alcohol fermentation temperatures. According to the record profile of the winery, the atmospheric temperature during the alcohol fermentation was higher than usual without a cooling system. Molina et al. [36] and Culleré et al. [37] reported that higher wine fermentation temperature interferes with the reactions of esters and increases the formation of acetaldehyde. Besides, the addition of $\mathrm{SO}_{2}$ before alcohol fermentation may affect the formation of acetaldehyde in wine. The Syrah wine from the Shangri-La region in this study was determined to have a lower concentration of esters and lower intensities of fruity odors. Mayr et al. [23] determined two Australian Syrah wines. The wine from the warmer Barossa Valley was found to have higher concentrations of ethyl propionate and 
oak-derived compounds, whereas the cooler Margaret River Syrah had above threshold concentrations of 2- and 3-methylbutanoic acid, as well as rotundone. $\beta$-Damascenone (OAV 24.4) was found with a lower odor activity value in YS than NS, as well as the fatty acids 2- and 3-methylbutyric acid (OAV 11.8).

Table 2. Volatile compounds quantified in two Syrah wine samples using Headspace GC-Flame Ionization Detector (HS-GC-FID) and Stir Bar Sorptive Extraction-GC-Mass Spectrometry (SBSE-GC-MS).

\begin{tabular}{|c|c|c|c|c|c|c|}
\hline \multirow[t]{2}{*}{ No. } & \multirow[t]{2}{*}{ Compounds } & \multirow{2}{*}{$\begin{array}{c}\text { Odor }{ }^{*} \\
\text { Threshold }\end{array}$} & \multicolumn{2}{|c|}{ Concentration $* *(\mu \mathrm{g} / \mathrm{L}$, mean $\pm \mathrm{SD})$} & \multicolumn{2}{|l|}{ OAV $* * *$} \\
\hline & & & NS & YS & NS & YS \\
\hline \multicolumn{7}{|c|}{ Ethyl esters of straight-chain fatty acid } \\
\hline 1 & ethyl acetate & 12,300 & $52,086 \pm 3892 a$ & $81,445 \pm 5481 b$ & 4.23 & 6.62 \\
\hline 2 & ethyl propionate & 2100 & $204 \pm 25$ & $184 \pm 47$ & $<0.1$ & $<0.1$ \\
\hline 3 & ethyl butanoate & 20 & $167 \pm 12 \mathrm{a}$ & $120 \pm 21 b$ & 8.36 & 6.02 \\
\hline 4 & ethyl hexanoate & 14 & $533 \pm 32 \mathrm{a}$ & $151 \pm 13 b$ & 38.1 & 10.8 \\
\hline 5 & ethyl octanoate & 5 & $275 \pm 22 \mathrm{a}$ & $58 \pm 8 b$ & 54.9 & 11.7 \\
\hline 6 & ethyl decanoate & 200 & $99.1 \pm 5.3 \mathrm{a}$ & $16.3 \pm 2 b$ & $0.1-0.5$ & $<0.1$ \\
\hline \multicolumn{7}{|c|}{ Ethyl esters of branched-chain fatty acid } \\
\hline 7 & ethyl isobutyrate & 15 & $264 \pm 24 \mathrm{a}$ & $164 \pm 29 \mathrm{~b}$ & 17.6 & 10.9 \\
\hline 8 & ethyl 2-methylbutanoate & 18 & $79.6 \pm 3.4 \mathrm{a}$ & $48.2 \pm 5.4 \mathrm{~b}$ & 4.42 & 2.68 \\
\hline 9 & ethyl isovalerate & 3 & $131 \pm 5 \mathrm{a}$ & $82 \pm 9 b$ & 43.8 & 27.3 \\
\hline \multicolumn{7}{|c|}{ Higher alcohol acetates } \\
\hline 10 & isobutyl acetate & 1800 & $78.1 \pm 6.3 \mathrm{a}$ & $61.0 \pm 10.1 b$ & $<0.1$ & $<0.1$ \\
\hline 11 & butyl acetate & 1600 & $23.4 \pm 1.1 \mathrm{a}$ & $14.6 \pm 1.6 b$ & $<0.1$ & $<0.1$ \\
\hline 12 & isoamyl acetate & 30 & $408 \pm 26 a$ & $244 \pm 13 \mathrm{~b}$ & 13.6 & 8.1 \\
\hline 13 & hexyl acetate & 670 & $3.31 \pm 0.37 \mathrm{a}$ & $0.76 \pm 0.14 b$ & $<0.1$ & $<0.1$ \\
\hline 14 & octyl acetate & 50,000 & $3.85 \pm 0.08 \mathrm{a}$ & $2.5 \pm 0.12 b$ & $<0.1$ & $<0.1$ \\
\hline \multicolumn{7}{|c|}{ Aromatic esters and others } \\
\hline 15 & phenethyl acetate & 73 & $33.3 \pm 0.9 \mathrm{a}$ & $20.3 \pm 1.2 b$ & $0.1-0.5$ & $0.1-0.5$ \\
\hline 16 & ethyl phenylacetate & 250 & $5.51 \pm 0.26$ & $5.92 \pm 0.26$ & $<0.1$ & $<0.1$ \\
\hline 17 & ethyl dihydrocinnamate & 1.6 & $1.68 \pm 0.58 \mathrm{a}$ & $0.41 \pm 0.26 \mathrm{~b}$ & 1.05 & $0.1-0.5$ \\
\hline 18 & ethyl cinnamate & 1.1 & $0.51 \pm 0.13$ & $0.37 \pm 0.23$ & $0.1-0.5$ & $0.1-0.5$ \\
\hline 19 & methyl anthranilate & 3 & $0.7 \pm 0.12 \mathrm{a}$ & $1.52 \pm 0.24 \mathrm{~b}$ & $0.1-0.5$ & $0.5-1$ \\
\hline 20 & ethyl anthranilate & 16 & $0.39 \pm 0.26 \mathrm{a}$ & $1.31 \pm 0.26 \mathrm{~b}$ & $<0.1$ & $<0.1$ \\
\hline 21 & methyl vanillate & 3000 & $5.68 \pm 2.62 \mathrm{a}$ & $13.5 \pm 0.14 b$ & $<0.1$ & $<0.1$ \\
\hline 22 & ethyl vanillate & 990 & $499 \pm 245$ & $898 \pm 307$ & $0.5-1$ & $0.5-1$ \\
\hline 23 & diethyl succinate & 120,000 & $11311 \pm 1078$ & $9736 \pm 958$ & $<0.1$ & $<0.1$ \\
\hline \multicolumn{7}{|c|}{ Alcohols } \\
\hline 24 & 1-propanol & 50,000 & $31,180 \pm 4642$ & $38,252 \pm 2941$ & $0.5-1$ & $0.5-1$ \\
\hline 25 & isobutyl alcohol & 40,000 & $52,872 \pm 5530$ & $47,188 \pm 4978$ & 1.32 & 1.18 \\
\hline 26 & isoamyl alcohol & 30,000 & $123,435 \pm 8642$ & $105,594 \pm 7374$ & 4.11 & 3.52 \\
\hline 27 & 1-hexanol & 8000 & $1046 \pm 35 a$ & $1279 \pm 63 \mathrm{~b}$ & $0.1-0.5$ & $0.1-0.5$ \\
\hline 28 & cis-3-hexen-1-ol & 1000 & $10.1 \pm 4.9$ & $12.7 \pm 3.4$ & $<0.1$ & $<0.1$ \\
\hline 29 & trans-2-hexen-1-ol & 1000 & $6.98 \pm 2.42$ & $8.77 \pm 3.16$ & $<0.1$ & $<0.1$ \\
\hline 30 & 1-octen-3-ol & 20 & $14.3 \pm 0.4 \mathrm{a}$ & $17.8 \pm 0.9 \mathrm{~b}$ & $0.5-1$ & $0.5-1$ \\
\hline 31 & benzyl alcohol & 200,000 & $218 \pm 52 \mathrm{a}$ & $595 \pm 80 \mathrm{~b}$ & $<0.1$ & $<0.1$ \\
\hline 32 & 2-phenethanol & 14,000 & $13793 \pm 1724 a$ & $9628 \pm 801 b$ & $0.5-1$ & $0.5-1$ \\
\hline \multicolumn{7}{|c|}{ Fatty acids } \\
\hline 33 & butanoic acid & 173 & $550 \pm 63$ & $484 \pm 70$ & 3.18 & 2.80 \\
\hline 34 & hexanoic acid & 420 & $1489 \pm 165 \mathrm{a}$ & $1076 \pm 140 \mathrm{~b}$ & 3.55 & 2.56 \\
\hline 35 & octanoic acid & 500 & $650 \pm 51$ & $579 \pm 68$ & 1.30 & 1.16 \\
\hline 36 & decanoic acid & 1000 & $122 \pm 14 \mathrm{a}$ & $72 \pm 16 b$ & $0.1-0.5$ & $<0.1$ \\
\hline 37 & 2-methylpropanoic acid & 2300 & $730 \pm 102 a$ & $544 \pm 96 b$ & $0.1-0.5$ & $0.1-0.5$ \\
\hline 38 & 2- and 3-methylbutyric acid & 33 & $564 \pm 134 \mathrm{a}$ & $390 \pm 43 b$ & 17.1 & 11.8 \\
\hline
\end{tabular}


Table 2. Cont.

\begin{tabular}{|c|c|c|c|c|c|c|}
\hline \multirow[t]{2}{*}{ No. } & \multirow[t]{2}{*}{ Compounds } & \multirow{2}{*}{$\begin{array}{c}\text { Odor }^{*} \\
\text { Threshold }\end{array}$} & \multicolumn{2}{|c|}{ Concentration ${ }^{* *}(\mu \mathrm{g} / \mathrm{L}$, mean $\pm \mathrm{SD})$} & \multicolumn{2}{|l|}{ OAV *** } \\
\hline & & & NS & YS & NS & YS \\
\hline \multicolumn{7}{|c|}{ Shikimic acid derivatives (volatile phenols) } \\
\hline 39 & guaiacol & 23 & $28.8 \pm 3.4 \mathrm{a}$ & $36.3 \pm 3.1 b$ & 1.25 & 1.58 \\
\hline 40 & 4-methylguaiacol & 65 & $1.98 \pm 0.97 \mathrm{a}$ & $9.56 \pm 0.15 b$ & $<0.1$ & $0.1-0.5$ \\
\hline 41 & 4-ethylguaiacol & 33 & $1.23 \pm 0.43 \mathrm{a}$ & $14.75 \pm 0.69 b$ & $<0.1$ & $0.1-0.5$ \\
\hline 42 & 4-vinylguaiacol & 1100 & $20 \pm 4.5$ & $17.8 \pm 1.4$ & $<0.1$ & $<0.1$ \\
\hline 43 & $o$-cresol & 31 & $5.86 \pm 2.2$ & $3.19 \pm 0.17$ & $0.1-0.5$ & $0.1-0.5$ \\
\hline 44 & $p$-cresol & 60 & $3.4 \pm 1.64$ & $4.44 \pm 0.28$ & $<0.1$ & $<0.1$ \\
\hline 45 & $m$-cresol & 68 & $3.11 \pm 1.69$ & $2.36 \pm 0.11$ & $<0.1$ & $<0.1$ \\
\hline 46 & eugenol & 6 & $6.71 \pm 1.25$ & $7.16 \pm 3.19$ & 1.12 & 1.19 \\
\hline 47 & isoeugenol & 6 & $0.44 \pm 0.23$ & $0.61 \pm 0.25$ & $<0.1$ & $0.1-0.5$ \\
\hline 48 & 4-ethylphenol & 440 & $1.76 \pm 0.61 \mathrm{a}$ & $101 \pm 11 b$ & $<0.1$ & $0.1-0.5$ \\
\hline 49 & 3-ethylphenol & 250 & $1.86 \pm 0.12 \mathrm{a}$ & $87 \pm 12 b$ & $<0.1$ & $0.1-0.5$ \\
\hline 50 & 4-vinylphenol & 180 & $56.9 \pm 13.3 \mathrm{a}$ & $81.2 \pm 6.6 \mathrm{~b}$ & $0.1-0.5$ & $0.1-0.5$ \\
\hline \multicolumn{7}{|c|}{ Terpenoids } \\
\hline 51 & linalool & 15 & $11.6 \pm 0.3 \mathrm{a}$ & $1.81 \pm 0.05 b$ & $0.1-0.5$ & $0.1-0.5$ \\
\hline 52 & $\alpha$-terpineol & 250 & $14.6 \pm 0.1 \mathrm{a}$ & $12 \pm 0.7 \mathrm{~b}$ & $<0.1$ & $<0.1$ \\
\hline 53 & citronellol & 100 & $1.76 \pm 0.03 \mathrm{a}$ & $0.66 \pm 0.05 b$ & $<0.1$ & $<0.1$ \\
\hline 54 & geraniol & 30 & $6.13 \pm 0.72 \mathrm{a}$ & $1.73 \pm 0.36 \mathrm{~b}$ & $0.1-0.5$ & $<0.1$ \\
\hline 55 & nerol & 300 & $8.98 \pm 0.65$ & $10.4 \pm 1.4$ & $<0.1$ & $<0.1$ \\
\hline 56 & rose oxide & 0.2 & $0.03 \pm 0.01$ & $0.04 \pm 0.03$ & $0.1-0.5$ & $0.1-0.5$ \\
\hline 57 & linalool oxide & 3000 & $1.72 \pm 0.36 \mathrm{a}$ & $5.69 \pm 0.49 \mathrm{~b}$ & $<0.1$ & $<0.1$ \\
\hline \multicolumn{7}{|c|}{$\mathrm{C}_{13}$-norisoprenoids } \\
\hline 58 & $\beta$-damascenone & 0.05 & $2.81 \pm 0.1 \mathrm{a}$ & $0.22 \pm 0.03 b$ & 56.1 & 24.4 \\
\hline 59 & $\beta$-ionone & 5 & $0.12 \pm 0.02$ & $0.09 \pm 0.08$ & $<0.1$ & $<0.1$ \\
\hline \multicolumn{7}{|c|}{ Ketone and lactones } \\
\hline 60 & $\gamma$-octalactone & 400 & $6.24 \pm 1.56$ & $5.15 \pm 0.6$ & $<0.1$ & $<0.1$ \\
\hline 61 & $\gamma$-nonalactone & 30 & $8.33 \pm 0.86$ & $11 \pm 1.98$ & $0.1-0.5$ & $0.1-0.5$ \\
\hline 62 & $\gamma$-decalactone & 88 & $0.6 \pm 0.04 \mathrm{a}$ & $1.34 \pm 0.29 \mathrm{~b}$ & $<0.1$ & $<0.1$ \\
\hline 63 & $\gamma$-undecalactone & 150 & $5.61 \pm 0.72 \mathrm{a}$ & $3.71 \pm 0.83 b$ & $<0.1$ & $<0.1$ \\
\hline 64 & cis-whiskylactone & 74 & $12.7 \pm 2.5 \mathrm{a}$ & $33.9 \pm 1.3 \mathrm{~b}$ & $0.1-0.5$ & $0.1-0.5$ \\
\hline 65 & trans-whiskylactone & 32 & $31.5 \pm 4.2$ & $58.3 \pm 2.1$ & $0.5-1$ & 1.82 \\
\hline 66 & 2-aminoacetophenone & 1.4 & $1.01 \pm 0.15$ & $1.18 \pm 0.11$ & $0.5-1$ & $0.5-1$ \\
\hline \multicolumn{7}{|c|}{ Aldehydes } \\
\hline 67 & acetaldehyde & 500 & $22,343 \pm 1397 a$ & $31,905 \pm 2231 b$ & 44.7 & 63.8 \\
\hline 68 & cinnamaldehyde & 1180 & $0.18 \pm 0.03 \mathrm{a}$ & $0.46 \pm 0.16 b$ & $<0.1$ & $<0.1$ \\
\hline 69 & vanillin & 200 & $88.8 \pm 6.7 \mathrm{a}$ & $110 \pm 8 b$ & $0.1-0.5$ & $0.5-1$ \\
\hline \multicolumn{7}{|c|}{ Methoxypyrazines } \\
\hline 70 & 3-isopropyl-2-methoxypyrazine & 0.015 & $0.001 \pm 0.0003$ & N.D. & $<0.1$ & $<0.1$ \\
\hline 71 & 3-sec-butyl-2-methoxypyrazine & 0.015 & N.D. & $0.0012 \pm 0.0004$ & $<0.1$ & $<0.1$ \\
\hline 72 & 3-isobutyl-2-methoxypyrazine & 0.002 & $0.0017 \pm 0.001$ & $0.0012 \pm 0.0004$ & $0.5-1$ & $0.5-1$ \\
\hline
\end{tabular}

* Odor threshold of the volatiles were presented in $\mu \mathrm{g} / \mathrm{L}$. They were measured in model wine, water/ethanol $(90+10, w / w)$ unless indicated, and referenced from the literature: [3,34,35,37-45]; ${ }^{* *}$ Different letters within rows indicates statistical differences by the Duncan test $(p<0.05) ;{ }^{* * *}$ OAV means odor activity value, calculated as the ratio between the concentration of the individual compound in wine and the threshold concentration of this substance.

The oak-derived compounds guaiacol (OAV 1.58) and eugenol (OAV 1.19) were detected to have similar concentrations in two Syrah wines. Compared with those in NS, ethyl acetate (OAV 6.62), trans-whiskylactone (OAV 1.82), vanillin (OAV 0.5-1), and phenolic compounds (all with OAV 0.5-1): 4-methylguaiacol, 4-ethylguaiacol, isoeugenol, 4-ethylphenol, and 3-ethylphenol were found to have higher odor activity values in YS. Fusel alcohols including propanol, isobutanol, 2- and 3-methyl-1-butanol, 1-hexanol, benzyl alcohol, and 2-phenethanol in wine are mainly formed through alcoholic fermentation from sugar and amino acid catabolism. They might show either positive or negative impacts on total aroma depending on the concentration level. It was reported that a level of higher alcohols below $300 \mathrm{mg} / \mathrm{L}$ confers a desirable complexity to the wine whereas concentrations over $400 \mathrm{mg} / \mathrm{L}$ have a negative effect [38]. In this study, both wines had fusel alcohols below $300 \mathrm{mg} / \mathrm{L}$, which contributed positively to the wine quality. 2-Phenylethanol that gave wine a positive rose aroma was also reported as a significant compound. In NS and YS wine, linalool and rose oxide have OAV 
between 0.1 and 0.5 ; those terpenoids are responsible for the odor of citrus (lemon) and floral aromas in wine. Furans and lactones with low odor thresholds in wine were always reported as the typical compounds in the aging wine. In this study, the low OAV of this group of compounds was consistent with the young wine vintage. Methoxypyrazine compounds 3-isopropyl-2-methoxypyrazine (IPMP), 2-sec-butyl-3-methoxypyrazine (SBMP), and 3-isobutyl-2-methoxypyrazine (IBMP) contributing green bell pepper or bean notes to wine had very low odor thresholds (IBMP, $2 \mathrm{ng} / \mathrm{L}$ ). The concentrations of methoxypyrazines in the sample wines did not reach the threshold, but they might be potential important odorants in wine due to the synergistic effect of the interaction between compounds [7,39].

\subsection{Sensory Evaluation of Syrah Wine Samples and Aroma Reconstitution Test}

Sensory descriptive analysis was performed to compare the aroma differences of the Syrah wine samples NS and YS, and to relate aroma compounds with sensory attributes. As shown in Figure 1, the two Syrah wines had similar intensities of floral, black pepper, green or bell pepper, sour, caramel, smoky, woody, spicy, and rancid or cheesy attributes. NS had a higher score of fruity (3.5) and berry (3.2) terms $(p<0.05)$ than that of YS $(2.7$ and 2.5 , respectively), which could be explained by the concentration differences of the esters with high OAVs and their synergetic interactions. For other attributes, the two wines showed similar results: the panelists could not detect the difference. Figure 1 illustrates that fruity, berry, floral, sour, caramel, smoky, and woody terms showed lower intensities in reconstitution wine than that in the wine samples.

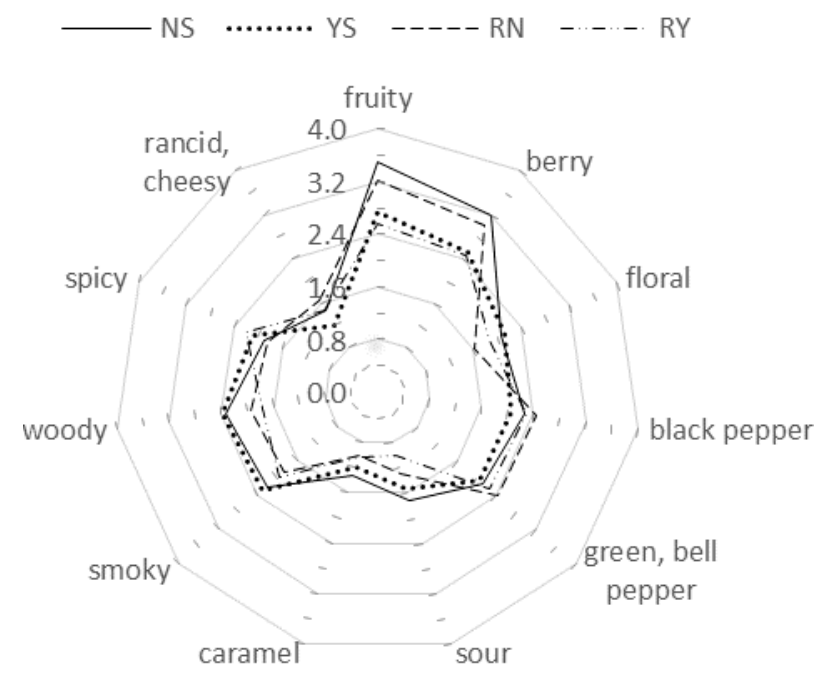

Figure 1. Aroma profiles of Syrah wine samples and reconstitution wine. Symbols in the figure: NS (Ningxia Syrah), YS (Yunnan Syrah), RN (Reconstitution NS), RY (Reconstitution YS).

\section{Materials and Methods}

\subsection{Wines}

Two popular commercial Syrah wines of vintage 2014 were kindly donated by wineries. NS was from the Ningxia region in northwest China. The basic composition of the wine was as follows: alcohol $14.1 \% \mathrm{v} / \mathrm{v}, \mathrm{pH} 3.48$, titratable acidity (TA, as tartaric acid) $6.78 \mathrm{~g} / \mathrm{L}$, volatile acidity (VA, as acetic acid) $0.78 \mathrm{~g} / \mathrm{L}$, total SO $64 \mathrm{mg} / \mathrm{L}$, glucose + fructose $(\mathrm{G}+\mathrm{F}) 1.2 \mathrm{~g} / \mathrm{L}$. YS was from a high altitude region, Yunnan Shangri-La in southwest China. The basic compositions: alcohol percentage of $13.6 \%$ by volume, pH 3.56, TA $6.51 \mathrm{~g} / \mathrm{L}$, VA 0.51g/L, total SO $291 \mathrm{mg} / \mathrm{L}, \mathrm{G}+\mathrm{F} 2.0 \mathrm{~g} / \mathrm{L}$. Both wine samples were fermented in stainless steel fermenters at $20-32{ }^{\circ} \mathrm{C}$, and the malolactic fermentation was performed ten days after the alcohol fermentation. Both wines were aged in the same type of France oak for half a year and bottled. Once received, the wine samples were stored in a $4{ }^{\circ} \mathrm{C}$ controlled temperature room. 


\subsection{Reagents and Chemical Standards}

Chemical standards of the compounds in this study were purchased from Sigma-Aldrich (St. Louis, MO, USA), TCI America (Portland, OR, USA), EKC Inc. (Rosemont, IL, USA), Alfa Aesar (Ward Hill, MA, USA), and EMD Chemical Inc. (Gibbstown, NJ, USA), and their purities were $>90 \%$ in all cases. The details are shown in a supplementary table. Milli-Q quality water was obtained from a Milli-Q purification system (Millipore, Boston, MA, USA). Methanol (HPLC grade) was from EM Science (Gibbstown, NJ, USA). Acetonitrile (HPLC grade) was bought from Omnisolv (McLean, VA, USA). Dichloromethane (HPLC grade) from Burdick \& Jackson (Muskegon, MI, USA) was freshly distilled before use. Tartaric acid was from Mallinckrodt Inc. (Paris, France). Anhydrous sodium sulfate and sodium chloride (99.9\%, ACS certified) were supplied by Mallinckrodt Baker. The LiChrolut-EN cartridge with a two-gram absorbent bed was packed in the laboratory.

Standard stock solutions were prepared in methanol individually except that fatty acids were in acetonitrile. Internal standard solution (IS) of 3,4-dimethylphenol and 4-octanol, was prepared at a concentration of $50 \mathrm{ppm}$ in methanol, separately. All the solutions were stored in dark bottles at $-20{ }^{\circ} \mathrm{C}$.

\subsection{LiChrolut-EN-SPE and Solvent-Assisted Flavor Evaporation (SAFE)}

The LiChrolut-EN cartridge was made by packing one-gram of resin into a $15 \mathrm{~mL}, 2 \mathrm{~cm}$ diameter reservoir (Thermo Scientific). The cartridge was conditioned with $10 \mathrm{~mL}$ of dichloromethane, air-dried, and then eluted with $10 \mathrm{~mL}$ of methanol, and finally washed with $10 \mathrm{~mL}$ of Milli-Q water. Two hundred and fifty milliliters of wine sample was percolated through the LiChrolut-EN under vacuum at $3 \mathrm{~mL}$ per min. The column was then washed with $10 \mathrm{~mL}$ of water and eluted with $20 \mathrm{~mL}$ of dichloromethane. The eluent was passed through the SAFE device (BÆNG; Glasbläserei Bahr, Manching, Germany) to remove the nonvolatile constituents at $50{ }^{\circ} \mathrm{C}$ under a vacuum of $2.80 \times 10^{-3}$ torr. The distillate was concentrated in a Kuderna-Danish concentrator in $40^{\circ} \mathrm{C}$ water bath with a Vigreaux column to approximately $5 \mathrm{~mL}$. After drying over anhydrous sodium sulfate and transferring, the extract was further concentrated to $0.5 \mathrm{~mL}$ with a gentle stream of nitrogen.

\subsection{GC-MS-Olfactometry Analysis}

The GC-O analyses were performed on an Agilent 6890 GC (Agilent Technologies Inc., Santa Clara, CA, USA) equipped with an Agilent 5973 mass selective detector and a Gerstel Olfactory Detection Port (ODP). One microliter concentrated extract was injected in split mode (split ratio 1:10) and separated by a ZB-Wax column $(30 \mathrm{~m} \times 0.25 \mathrm{~mm}$ i.d., $0.50 \mu \mathrm{m}$ film thickness, Phenomenex, Torrance, CA, USA). Helium was used as the carrier gas at a constant flow rate of $2.5 \mathrm{~mL} / \mathrm{min}$. At the exit of the capillary column, the effluents were split 1:1 (by volume) into a sniffing port and a MS detector. The GC injector and ODP temperature were both set at $250{ }^{\circ} \mathrm{C}$. The oven temperature was programed at $40{ }^{\circ} \mathrm{C}$ for a $4 \mathrm{~min}$ holding and ramped up to $100{ }^{\circ} \mathrm{C}$ at a rate of $4{ }^{\circ} \mathrm{C} / \mathrm{min}$, then $3{ }^{\circ} \mathrm{C} / \mathrm{min}$ to $230{ }^{\circ} \mathrm{C}$ with a $10 \mathrm{~min}$ holding. The MS transfer line and ion source temperature were $250^{\circ} \mathrm{C}$ and $230^{\circ} \mathrm{C}$, respectively. Electron ionization mass spectrometric data from $m / z$ 35-350 were collected using a scan rate of $5.27 / \mathrm{s}$, with an ionization voltage of $70 \mathrm{eV}$. Three experienced panelists (two females and one male, with over $30 \mathrm{~h}$ of training) were selected for the GC-O analysis. The retention time, odor descriptor, and its intensity (5-point scale from 1 to 5 represent very weak, weak, moderate, strong, very strong) were recorded. Each sniffing session lasted $1 \mathrm{~h}$ and the panelists smelled each extract sample twice. The average intensity of the descriptors was calculated. A standard mixture of $n$-alkane $C_{5}-C_{30}$ was prepared and analyzed under the same GC conditions above. Retention Indices (RI) were calculated in accordance with a modified Kovats method based on individual retention times from the lab using pure reference compounds. Mass spectra of unknown compounds were compared with those present in the Wiley 275.L database (Agilent Technologies Inc.). 


\subsection{Quantitative Analysis of the Key Aroma-Active Compounds}

\subsubsection{Static Headspace-GC-FID Analysis}

Acetaldehyde, ethyl acetate, propanol, isobutyl alcohol, isoamyl acetate, and isoamyl alcohol were quantitated using the static headspace-GC-FID method described previously [46] due to their high concentrations in the sample. A Varian CP 3800 gas chromatograph equipped with a flame ionization detector (Varian, Inc., Palo Alto, CA, USA) was used. One milliliter of wine was added into a $20 \mathrm{~mL}$ auto sampler vial and $20 \mu \mathrm{L}$ of internal standard (IS, $5 \mathrm{mg} / \mathrm{L}$ methyl propionate in methanol) was spiked. Samples were equilibrated at $70{ }^{\circ} \mathrm{C}$ for 15 minutes with agitation at $500 \mathrm{rpm}$. One thousand microliters of the headspace sample was injected using a heated $\left(70{ }^{\circ} \mathrm{C}\right)$ gastight syringe $(2.5 \mathrm{~mL})$ in split mode 10:1. Separation was performed by a DB-FFAP capillary column $(30 \mathrm{~m} \times 0.32 \mathrm{~mm}$ i.d., $0.5 \mu \mathrm{m}$ film thickness, Agilent Technologies). Helium was used as the carrier gas at a constant rate of $1.5 \mathrm{~mL}$ per minute. The oven temperature was set at $35^{\circ} \mathrm{C}$ for $4 \mathrm{~min}$ holding, raised to $150{ }^{\circ} \mathrm{C}$ at a rate of $10^{\circ} \mathrm{C} / \mathrm{min}$, and held at the final temperature for $5 \mathrm{~min}$. The injector and detector temperature were both set at $250{ }^{\circ} \mathrm{C}$, respectively. A standard calibration curve was prepared by spiking known amounts of standards into one $\mathrm{mL}$ of synthetic wine $(12 \%$ ethanol $(v / v), 3.5 \mathrm{~g} / \mathrm{L}$ tartaric acid, $\mathrm{pH} 3.5)$ and $20 \mu \mathrm{L}$ of IS (5 mg/L methyl propionate) was added. Data were collected by the Varian Star workstation. Standard curves and sample concentrations were calculated using interactive graphics.

\subsubsection{SBSE-GC-MS Analysis}

For those compounds having low concentration or low affinity, the quantitation was conducted by the SBSE-GC-MS technique as described previously $[47,48]$. The comparison of two Twisters (PDMS and EG) is shown in the supplementary materials. A preconditioned PDMS coated stir bar (Twister) (10 mm $\times 0.5 \mathrm{~mm}$, Gerstel Inc., Linthicum, MD, USA.) or an EG coated stir bar (0.5 mm film thickness, $10 \mathrm{~mm}$ length, Gerstel Inc.) was used to extract the aroma compounds. Ten milliliters of wine was pipetted into a $40 \mathrm{~mL}$ glass vial and diluted with $10 \mathrm{~mL}$ of saturated $\mathrm{NaCl}$ solution, and $20 \mu \mathrm{L}$ of IS (50 ppm 4-octanol for PDMS stir bar set, 50 ppm 3,4-dimethlyphenol for EG stir bar set) solution was added. A PDMS or EG stir bar was then placed into the vial and stirred for $3 \mathrm{~h}$ at $1000 \mathrm{rpm}$ at room temperature. After extraction, the stir bar was picked up from the vial, rinsed with Milli-Q water, dried with a Kimwipe, and transferred into a thermal desorption unit (TDU) for GC-MS analysis. Each sample was analyzed in triplicate. Analysis of the absorbed volatile compounds were performed on an Agilent 7890 GC coupled with a 5975 mass selective detector, and a Gerstel MPS-2 multipurpose TDU auto sampler with a CIS-4 cooling injection system (Gerstel Inc.). The analytes were thermally desorbed at the TDU in splitless mode. The CIS- 4 was cooled to $-80{ }^{\circ} \mathrm{C}$ with liquid nitrogen during the sample desorption, and then heated at $10^{\circ} \mathrm{C} / \mathrm{s}$ to $250{ }^{\circ} \mathrm{C}$ and held for $10 \mathrm{~min}$ for the PDMS bar, or to $220^{\circ} \mathrm{C}$ for the EG bar. Solvent vent mode was used during the injection with a split vent flow of $50 \mathrm{~mL} / \mathrm{min}$. A ZB-WAX capillary column $(30 \mathrm{~m} \times 0.25 \mathrm{~mm}$ i.d., $0.5 \mu \mathrm{m}$ film thickness, Phenomenex, Torrance, CA) was used. The oven temperature program was set at $40{ }^{\circ} \mathrm{C}$ for $4 \mathrm{~min}$, raised to $230{ }^{\circ} \mathrm{C}$ at $4{ }^{\circ} \mathrm{C} / \mathrm{min}$, and held for $15 \mathrm{~min}$. A constant helium flow of $2 \mathrm{~mL} / \mathrm{min}$ was used. The MS transfer line and ion source temperatures were $280^{\circ} \mathrm{C}$ and $230{ }^{\circ} \mathrm{C}$, respectively. A standard calibration curve was prepared by spiking known amounts of standards into $10 \mathrm{~mL}$ of synthetic wine and $10 \mathrm{~mL}$ of saturated $\mathrm{NaCl}$ solution with $20 \mu \mathrm{L}$ of IS. Each sample was analyzed in triplicate and the results were calculated through Chemstation software (v.10.1) (Agilent Technologies).

\subsection{Sensory Evaluation of Wines and Aroma Reconstitution Test}

The sensory evaluation of the two wine samples was conducted based on the method by Tao et al. [49]. The panel was trained over 50 days using a "Le Nez du Vin" aroma kit and 11 judges (4 males and 7 females) were selected. The Quantitative Descriptive Analysis (QDA) was performed to pick up the most important terms to describe the aroma characters of the wine samples in this study. The top (high MF values) 11 descriptors: fruity, berry, floral, black pepper, green or bell pepper, 
sour, caramel, smoky, woody, spicy, and rancid or cheesy were selected to describe the aroma of Syrah wine in this study. Sample wines in a balanced and completed block design were presented (in triplicate) to the panelists. They were required to use the 5 to 6 most significant terms as listed in Li et al. [37] to describe the wine aroma. Panelists were also asked to score the intensity of each term using a 5-point scale: (0) not detected; (1) weak, hardly recognizable note; (2) clear, but weak; (3) clear but not an intense note; and (4) intense note. The data processed were a mixture of intensity and frequency of detection ("modified frequency", $M F$ ), which was calculated with the formula proposed by Tao et al. [49,50]:

$$
M F=\sqrt{F(\%) I(\%)}
$$

$F(\%)$ is the detection frequency of an aromatic attribute expressed as a percentage; $I(\%)$ is the average intensity expressed as a percentage of the maximum intensity.

The aroma reconstitution test was conducted as described by Chen et al. [18] to resemble the wine according to the quantitative analysis and OAVs. Compounds with high OAVs $(\geq 0.5)$ were reconstituted with the concentration in the matrix of synthetic wine $(14 \%$ ethanol $(v / v), 3.5 \mathrm{~g} / \mathrm{L}$ tartaric acid, $\mathrm{pH}$ 3.5), labeled as RN and RY for NS and YS, respectively.

\subsection{Statistical Analysis}

The volatile compounds identified and quantified were listed in the table which was formed by Microsoft Office Excel 2013, and so was the mean value, standard deviation, and the OAVs. The concentration differences of volatiles between samples were determined using one-way analysis of variance (ANOVA) established by the Student's $t$ test at a significance level of $\leq 0.05$, carried out using SPSS 20.0 (IBM, Armonk, NY, USA).

\section{Conclusions}

In this study, ethyl 2-methylpropanoate, ethyl 3-methylbutanoate, 3-methylbutyl acetate, 2- and 3-methyl-1-butanol, ethyl hexanoate, ethyl octanoate, 2-phenethyl acetate, methional, 3-methylbutanoic acid, hexanoic acid, octanoic acid, $\beta$-damascenone, guaiacol, 2-phenylethanol, trans-whiskylactone, 4-ethylguaiacol, eugenol, 4-ethylphenol, and sotolon were detected as the most significant aroma compounds in the GC-O analysis. $\beta$-Damascenone, ethyl octanoate, acetaldehyde, ethyl isovalerate, ethyl hexanoate, ethyl isobutyrate, isoamyl acetate, butanoic acid, 2- and 3-methylbutyric acid, hexanoic acid, and octanoic acid with high OAVs were detected as the most significant aroma contributors in the SBSE-GC-MS analysis. The candidate grape-derived compounds increased the understanding of Syrah wine produced in China. The fermentation-derived and oak-derived compounds identified in this study help winemakers and wine chemists better understand the aroma compositions and aroma profiles of the wine.

By comparing the odor intensities in GC-O, OAVs in the quantitative analysis, and scores of descriptors in the sensory evaluation, a more thorough understanding of the correlation of compounds and aroma was formed. Important aroma contributors: ethyl 2-methylbutyrate, ethyl hexanoate, ethyl octanoate, ethyl decanoate, 3-methylbutyl acetate, guaiacol, eugenol, and decanoic acid were detected at higher odor intensities in the sample Syrah extract from Helan Mountain as compared to Shangri-La. The quantitative analysis and OAV study also showed that most of the ethyl esters and acetate esters were found with higher OAVs in the Syrah wine of Helan Mountain rather than the wine from Shangri-La. It also should be noticeable that the Syrah wine from Ningxia in this study showed stronger fruity characteristics in the sensory evaluation study, which is consistent with the GC-O and quantitative analysis.

Acknowledgments: This work was funded by the China National Science Fund (31471708) and Shaanxi Industrial Technology System for Grapes. The authors also acknowledge the China Scholarship Council (No. 201406300126). 
Author Contributions: Pengtao Zhao conceived and designed the experiments; Pengtao Zhao and Jinxin Gao performed the chemical and sensory experiments; Pengtao Zhao wrote the paper. All authors have read and approved the final version of the manuscript.

Conflicts of Interest: The authors declare no conflict of interest.

\section{References}

1. García-Muñoz, S.; Muñoz-Organero, G.; Cabello, F. Sensory characterisation and factors influencing quality of wines made from 18 minor varieties (Vitis vinifera L.). Food Qual. Prefer. 2014, 32, 241-252. [CrossRef]

2. Sokolowsky, M.; Rosenberger, A.; Fischer, U. Sensory impact of skin contact on white wines characterized by descriptive analysis, time-intensity analysis and temporal dominance of sensations analysis. Food Qual. Prefer. 2015, 39, 285-297. [CrossRef]

3. Aznar, M.; López, R.; Cacho, J.; Ferreira, V. Prediction of aged red wine aroma properties from aroma chemical composition. Partial least squares regression models. J. Agric. Food Chem. 2003, 51, 2700-2707. [CrossRef] [PubMed]

4. Jackson, R.S. Wine Science, 3rd ed.; Elsevier Academic Press: Boston, MA, USA, 2014; pp. 189-233.

5. Zhu, F.; Du, B.; Li, J. Grape and Wine Biotechnology: Aroma Compounds in Wine. Agric. Biol. Sci. 2016. [CrossRef]

6. Ferreira, V.; Sáenz-Navajas, M.-P.; Campo, E.; Herrero, P.; Fuente, A.; Fernández-Zurbano, P. Sensory interactions between six common aroma vectors explain four main red wine aroma nuances. Food Chem. 2016, 199, 447-456. [CrossRef] [PubMed]

7. Robinson, A.L.; Ebeler, S.E.; Heymann, H.; Boss, P.K.; Solomon, P.S.; Trengove, R.D. Interactions between wine volatile compounds and grape and wine matrix components influence aroma compound headspace partitioning. J. Agric. Food Chem. 2009, 57, 10313-10322. [CrossRef] [PubMed]

8. Arvisenet, G.; Guichard, E.; Ballester, J. Taste-aroma interaction in model wines: Effect of training and expertise. Food Qual. Prefer. 2016, 52, 211-221. [CrossRef]

9. Villamor, R.R. The Impact of Wine Components on the Chemical and Sensory Properties of Wines. Ph.D. Thesis, Washington State University, Spokane, WA, USA, May 2012.

10. Panighel, A.; Flamini, R. Solid Phase Extraction and Solid Phase Microextraction in grape and wine volatile compounds analysis. Sample Prep. 2015, 2, 55-65. [CrossRef]

11. Thurman, E.M.; Mills, M.S. Solid-Phase Extraction: Principles and Practice; Wiley: New York, NY, USA, 1998; pp. 99-121.

12. Andujar-Ortiz, I.; Moreno-Arribas, M.V.; Martín-Alvarez, P.J.; Pozo-Bayón, M.A. Analytical performance of three commonly used extraction methods for the gas chromatography-mass spectrometry analysis of wine volatile compounds. J. Chromatogr. A 2009, 1216, 7351-7357. [CrossRef] [PubMed]

13. Kawaguchi, M.; Takatsu, A.; Ito, R.; Nakazawa, H. Applications of stir-bar sorptive extraction to food analysis. TrAC Trend Anal. Chem. 2013, 45, 280-293. [CrossRef]

14. Zhou, Q. , Qian, Y.; Qian, M.C. Analysis of volatile phenols in alcoholic beverage by ethylene glycol-polydimethylsiloxane based stir bar sorptive extraction and gas chromatography-mass spectrometry. J. Chromatogr. A 2015, 1390, 22-27. [CrossRef] [PubMed]

15. Yunyun, N.; Albinus, T. Comparison of EG-Silicone-SBSE and Derivatization-PDMS-SBSE for the Analysis of Phenolic Compounds and Off-flavors in Water; Gerstel: Mülheim an der Ruhr, Germany, 2012.

16. Ledderhof, D.; Reynolds, A.G.; Manin, L.; Brown, R. Influence of water status on sensory profiles of Ontario Pinot noir wines. Food Res. Int. 2013, 57, 881-891. [CrossRef]

17. Chen, S.; Xu, Y.; Qian, M.C. Aroma characterization of Chinese rice wine by gas chromatography-olfactometry, chemical quantitative analysis, and aroma reconstitution. J. Agric. Food Chem. 2013, 61, 11295-11302. [CrossRef] [PubMed]

18. Plutowska, B.; Wardencki, W. Application of gas chromatography-olfactometry (GC-O) in analysis and quality assessment of alcoholic beverages-A review. Food Chem. 2008, 107, 449-463. [CrossRef]

19. Ferreira, V.; Aznar, M.; López, R.; Cacho, J. Quantitative Gas Chromatography-Olfactometry Carried out at Different Dilutions of an Extract. Key Differences in the Odor Profiles of Four High-Quality Spanish Aged Red Wines. J. Agric. Food Chem. 2001, 49, 4818. [CrossRef] [PubMed] 
20. Sáenz-Navajas, M.P.; Avizcuri, J.M.; Ballester, J.; Fernández-Zurbano, P.; Ferreira, V.; Peyron, D.; Valentin, D. Sensory-active compounds influencing wine experts' and consumers' perception of red wine intrinsic quality. LWT Food Sci. Technol. 2015, 60, 400-411. [CrossRef]

21. Guisard, Y.; Blackman, J.; Clark, A.; Holzapfel, B.; Rawson, A.; Rogiers, S.; Schmidtke, L.; Smith, J.; Steel, C. Viticulture and Wine Science; Horticulture: Plants for People and Places; Springer: Amsterdam, The Netherlands, 2014; Volume 1, pp. 197-261.

22. Pérez-Magariño, S.; Ortega-Heras, M.; Bueno-Herrera, M.; Martínez-Lapuente, L.; Guadalupe, Z.; Ayestarán, B. Grape variety, aging on lees and aging in bottle after disgorging influence on volatile composition and foamability of sparkling wines. LWT Food Sci. Technol. 2015, 61, 47-55. [CrossRef]

23. Mayr, C.M.; Geue, J.P.; Holt, H.E.; Pearson, W.P.; Jeffery, D.W.; Francis, I.L. Characterization of the key aroma compounds in Shiraz wine by quantitation, aroma reconstitution, and omission studies. J. Agric. Food Chem. 2014, 62, 4528-4536. [CrossRef] [PubMed]

24. Galipeau, B.A.; Simonelli, J.; Paladino, S. Balancing Income, Food Security, and Sustainability in Shangri-La: The Dilemma of Monocropping Wine Grapes in Rural China. Cult. Agric. Food Environ. 2016, 37, 74-83. [CrossRef]

25. Chen, W.; Shang, H.; Zhou, J.; Feng, X.; Zhou, T. Ecological adaptability of wine grape at the eastern foot of Helan mountain. Xibei Zhiwu Xuebao 2007, 27, 1855-1860.

26. González, Á.M.; González-Barreiro, C.; Cancho-Grande, B.; Simal-Gándara, J. Relationships between Godello white wine sensory properties and its aromatic fingerprinting obtained by GC-MS. Food Chem. 2011, 129, 890-898. [CrossRef] [PubMed]

27. Sáenz-Navajas, M.P.; Martín-López, C.; Ferreira, V.; Fernández-Zurbano, P. Sensory properties of premium Spanish red wines and their implication in wine quality perception. Aust. J. Grape Wine Res. 2011, 17, 9-19. [CrossRef]

28. Pozo-Bayón, M.Á.; Muñoz-González, C.; Esteban-Fernández, A. Wine Preference and Wine Aroma Perception; Springer International Publishing: Basel, Switzerland, 2016; pp. 83-103.

29. Pineau, B.; Barbe, J.C.; Van, L.C.; Dubourdieu, D. Which impact for $\beta$-damascenone on red wines aroma? J. Agric. Food Chem. 2007, 55, 4103-4108. [CrossRef] [PubMed]

30. Yuan, F.; Qian, M.C. Development of $\mathrm{C}_{13}$-norisoprenoids, carotenoids and other volatile compounds in Vitis vinifera L. Cv. Pinot noir grapes. Food Chem. 2016, 192, 633-641. [CrossRef] [PubMed]

31. Condurso, C.; Cincotta, C.F.; Tripodi, G.; Sparacio, A.; Giglio, D.M.L.; Sparla, S.; Verzera, A. Effects of cluster thinning on wine quality of Syrah cultivar (Vitis vinifera L.). Eur. Food Res. Tchnol. 2016, 242, 1-8. [CrossRef]

32. Flamini, R.; Traldi, P.; Flamini, R.; Traldi, P. Mass spectrometry in grape and wine chemistry. In Volatile and Aroma Compounds in Wines; John Wiley \& Sons, Inc.: New York, NY, USA, 2010; pp. 117-162.

33. Souid, I.; Hassene, Z.; Palomo, E.S.; Perezcoello, M.S.; Ghorbel, A. Varietal aroma compounds of Vitis vinifera cv. Khamri grown in Tunisia. J. Food Qual. 2007, 30, 718-730. [CrossRef]

34. Guth, H. Quantitation and sensory studies of character impact odorants of different white wine varieties. J. Agric. Food Chem. 1997, 45, 3027-3032. [CrossRef]

35. Parker, M.; Osidacz, P.; Baldock, G.A.; Hayasaka, Y.; Black, C.A.; Pardon, K.H.; Jeffery, D.W.; Geue, J.P.; Herderich, M.J.; Francis, I.L. Contribution of several volatile phenols and their glycoconjugates to smoke-related sensory properties of red wine. J. Agric. Food Chem. 2012, 60, 2629-2637. [CrossRef] [PubMed]

36. Molina, A.M.; Swiegers, J.H.; Varela, C.; Pretorius, I.S.; Agosin, E. Influence of wine fermentation temperature on the synthesis of yeast-derived volatile aroma compounds. Appl. Microbiol. Biotechnol. 2007, 77, 675-687. [CrossRef] [PubMed]

37. Culleré, L.; Cacho, J.; Ferreira, V. An assessment of the role played by some oxidation-related aldehydes in wine aroma. J. Agric. Food Chem. 2007, 55, 876-881. [CrossRef] [PubMed]

38. Li, H.; Tao, Y.S.; Wang, H.; Zhang, L. Impact odorants of Chardonnay dry white wine from Changli County (China). Eur. Food Res. Tchnol. 2008, 227, 287-292. [CrossRef]

39. Boutou, S.; Chatonnet, P. Rapid headspace solid-phase microextraction/gas chromatographic/mass spectrometric assay for the quantitative determination of some of the main odorants causing off-flavours in wine. J. Chromatogr. A 2007, 1141, 1-9. [CrossRef] [PubMed]

40. Ferreira, V.; López, R.; Cacho, J.F. Quantitative determination of the odorants of young red wines from different grape varieties. J. Sci. Food Agric. 2000, 80, 1659-1667. [CrossRef] 
41. Ferreira, V.; Ortín, N.; Escudero, A.; López, R.; Cacho, J. Chemical characterization of the aroma of Grenache rose wines: Aroma extract dilution analysis, quantitative determination, and sensory reconstitution studies. J. Agric. Food Chem. 2002, 50, 4048-4054. [CrossRef] [PubMed]

42. La Guerche, S.; Dauphin, B.; Pons, M.; Blancard, D.; Darriet, P. Characterization of some mushroom and earthy off-odors microbially induced by the development of rot on grapes. J. Agric. Food Chem. 2006, 54, 9193-9200. [CrossRef] [PubMed]

43. López, R.; Aznar, M.; Cacho, J.; Ferreira, V. Determination of minor and trace volatile compounds in wine by solid-phase extraction and gas chromatography with mass spectrometric detection. J. Chromatogr. A 2002, 966, 167-177. [CrossRef]

44. Návojská, J.; Brandes, W.; Nauer, S.; Eder, R.; Frančáková, H. Influence of different oak chips on aroma compounds in wine. J. Microbiol. Biotechnol. Food Sci. 2012, 1, 957.

45. Peinado, R.A.; Moreno, J.; Bueno, J.E.; Moreno, J.A.; Mauricio, J.C. Comparative study of aromatic compounds in two young white wines subjected to pre-fermentative cryomaceration. Food Chem. 2004, 84, 585-590. [CrossRef]

46. He, J.; Zhou, Q.; Peck, J.; Soles, R.; Qian, M.C. The effect of wine closures on volatile sulfur and other compounds during post-bottle ageing. Flavour Frag. J. 2013, 28, 118-128. [CrossRef]

47. Fang, Y.; Qian, M.C. Quantification of selected aroma-active compounds in Pinot noir wines from different grape maturities. J. Agric. Food Chem. 2006, 54, 8567-8573. [CrossRef] [PubMed]

48. Qian, M.C.; Fang, Y.; Shellie, K. Volatile composition of Merlot wine from different vine water status. J. Agric. Food Chem. 2009, 57, 7459-7463. [CrossRef] [PubMed]

49. Tao, Y.S.; Liu, Y.-Q.; Li, H. Sensory characters of Cabernet Sauvignon dry red wine from Changli County (China). Food Chem. 2009, 114, 565-569. [CrossRef]

50. State Bureau of Technical Supervision. Sensory Analysis-Methodology-Initiation and Training of Assessors in the Dection and Recongnition of Odours. Available online: http:/ /111.26.194.81:82/fdbzfw/spgjbz/7194. jhtml (accessed on 23 June 2017).

Sample Availability: Samples of Syrah wine are available from author H.L. Standard compounds are available from M.Q.

(C) 2017 by the authors. Licensee MDPI, Basel, Switzerland. This article is an open access article distributed under the terms and conditions of the Creative Commons Attribution (CC BY) license (http://creativecommons.org/licenses/by/4.0/). 